\title{
A Path Analysis of Learning-Motivation-Behavior Affecting Factors Among Higher Vocational College Students
}

\author{
Mengxuan Xiao ${ }^{1} \&$ Shaoyun Long ${ }^{1}$ \\ ${ }^{1}$ School of Foreign Languages, Jiangxi Normal University, Nanchang, China \\ Correspondence: Shaoyun Long, Foreign Languages college, Jiangxi Normal University, 99\#, Ziyang Road, \\ Nanchang, Jiangxi Province, China. E-mail: 1512051601@qq.com
}

Received: July 31, 2019 Accepted: August 23, 2019 Online Published: August 26, 2019

doi:10.5539/ells.v9n3p47 URL: https://doi.org/10.5539/ells.v9n3p47

\begin{abstract}
This paper made an investigation into the motivation-behaviors affecting factors of the carefully-selected 20 willing learners, 20 unwilling learners among 597 students from foreign languages department in two higher vocational colleges. An analysis has been made in the learning-motivation-behavior affecting factors route paths of students in higher vocational colleges. We found that there are universality and individuality in factors that predict the motivation behavior of three categories of students. Predictive factors of motivational behavior include motivation levels and learning strategies. The regression effects of learning strategies on motivational behavior are the greatest in the three categories of path analysis. It shows that learning strategies determine the performance of their motivational behavior, at the same time, it shows individual variance.
\end{abstract}

Keywords: questionnaire, correlation analysis, motivation-behaviors, route analysis, inner modes

\section{Introduction}

\subsection{Connotation of Learning Motivation}

In the history of the study of motivation, some pioneers in physiology and philosophy have attempted to explain the complex factors that motivate and cause people's behavior from the perspective of physiology or philosophy. In earlier studies, many psychologists believed that psychology is composed of knowledge (cognition), emotion (emotion) and meaning (motivation). The rise of behaviorism in the 20th century emphasizes that behavior is a response to environmental stimuli, so some scholars put forward the concept of drive to explain the internal state of driving behavior. Because of its complexity, modern educational psychology endows learning motivation with more meanings.

Foreign scholars explained the meaning of learning motivation from the function of learning motivation: According to Dornyei (2008), learning motivation is defined as a dynamic process, from stimulating individual desire, keep learning behavior, and achieve the expected goals to the termination of desire or learning behavior affected by other factors. Hurl (2014) proposed that learning motivation is the psychological tendency to cause and maintain individual learning behaviors to meet learning needs. Domestic scholars point out that learning motivation is an important indicator of students' learning behavior. Zhang (2016) defined learning motivation as the internal psychological process that causes and maintains students' learning activities so that the learning activities tend to be consistent with the goals set by teachers. Some educators believe that learning motivation includes many aspects.

\subsection{Literature Review}

Although scholars have different understanding of learning motivation, but all agree that learning motivation plays an important role in learning behavior, it can arouse learning behavior and maintain learning behavior, select learning tasks, and reflect the role of students real achievements or performance, which was confirmed by a large amount of motivation theories and empirical studies.

Firstly, at present, the achievement motivation of students has become an important research object. The research on achievement motivation at home and abroad mainly focuses on three aspects: one is the relationship between achievement motivation and academic performance. Lasarus showed that high achievers generally achieve high grades. Students with strong achievement motivation are more likely to stick to learning than those with weak achievement motivation, and their academic performance is better. Many domestic studies have consistently 
found that achievement motivation can enhance learning efficiency, and achievement motivation level is highly predictive of students' academic performance. For example, the research of Guo and Wang (2015) points out that achievement motivation has a significant positive correlation with students' learning perseverance, learning efficiency and academic performance, and is an important factor determining students' efforts and influencing their academic achievements.

Secondly, environmental factors (such as school, classroom atmosphere, family, etc.) are significantly related to the individual's achievement motivation. Sun et al. took junior high school students as subjects, and the results showed that the parenting style was not significantly related to their achievement motivation, but the junior high school students' achievement motivation was related to the emotional warmth of fathers in the parenting style.

Thirdly, based on the role of learning interest in promoting learning, many studies at home and abroad have discussed learning interest as an important driving force for learning activities. Sawrey and Telford point out that interest is another aspect of motivation. Eggen and Kauchak (2008) believe that interest represents a typical way, that is, to understand novel, uncertain or confusing phenomena with purpose or goal. Lin (2014) pointed out that interest is an important motivation to promote people to know things and explore the truth.

In the past, most motivation studies focused on test scores and seldom discussed the relationship between motivation and belief and academic cognition. In addition, previous motivation studies focused on classroom factors that could predict students' motivation and achievement, but lacked the ability to examine students' achievements through subject scores and classroom test scores, so these studies could not truly test the motivation components of special subject tasks. Firstly, learning motivation is proposed from a single theoretical basis, which makes the meaning of learning motivation incomplete and fails to fully reflect the multidimensional nature of learning motivation. Secondly, there is little focus on specific emotional factors as a behavioral tendency.

\subsection{Research Questions}

1) What are the affecting factors of learning motivation among the higher vocational college students?

2) What are the path patterns between these affecting factors among the higher vocational college students?

\section{Methods}

\subsection{Research Participants}

\section{(1) Selection step}

First step: to examine final exam results that related to professional courses in the first semester and English college entrance examination results (provided by the head teacher); to observe students' learning behaviors, including class and self-study attendance, homework, group activities, and note-taking (Visiting the teachers' courses of major subjects and observing how the teacher managing the class); to inspect students' self-confidence, learning interest, learning attitude and daily observation through the monitor, commissary in charge of studies, head teachers, major teachers and other managers.

Second Step: Students have consensus among monitor, commissary in charge of studies, head teachers, major teachers, and they are taken as subjects, or eliminated.

Third step: let the selected students in step two do self-judgments, and make a contrast between that results with the evaluation which monitor, commissary in charge of studies, head teachers and major teachers had concluded. Both of them are same, the students are selected as subjects. The rest of students whose EPQ-L is high in Eysenck Personality Questionnaire would also be selected.

\section{(2) Standard of the selected three categories of students}

Reference standard of weary students: learning focus can't be concentrated, and there is hardly any interest in learning, and the initiative is not strong, and students cannot study in an assiduous and persevering way; learning behavior is lazy, and the sense of discipline is not strong, and there is very little time to learn English in extracurricular way. Most students often lag behind other classmates in academic record (failing or barely passing) and have an inferiority complex heart.

Reference standard of unwilling students: sometimes learning focus is concentrated and students can study in an initiative way, and it is difficult to learn constantly; sometimes interested and diligent, and the sense of discipline is strong, learning behavior is tense or lax every now and then, the majority of students lie in lower half of the class in the academic performance and self-confidence is in general.

Reference standard of willing students: learning focus is more concentrated, learning initiative is strong, and 
students can persevere in learning; interest remains perpetually high, and students are diligent, and they have a strong sense of discipline. Learning behavior is tense and orderly, and students spend much time in learning English in extracurricular way. Most students' academic records are upstream, and they have strong self-confidence.

\section{(3) Subjects selected}

According to the methods above, 20 weary students, 20 unwilling students, 20 willing students (A total of 60 students) are selected as subjects from the two vocational colleges which chose 597 students including first-year students at five-year vocational college and first-year and second-year students at higher vocational college. Specifically speaking, there are 5 weary students, 5 unwilling students and 5 willing students among first-year students at five-year vocational college students (6 males and 9 females); there are 10 weary students, 10 unwilling students and 10 willing students among first-year students at higher vocational college (8 males and 22 females), and 5 weary students, 5 unwilling students and 5 willing students among second-year students (5 males, 10 females).

\subsection{Research Instruments}

(1) Self-Efficacy Questionnaire: Referring to self-efficacy questionnaire draw up by Pintrich and Degroot, and combining with the actual interview towards foreign language students in vocational colleges, and establishing 11 questions. Ways of evaluation adopt a six-point system, the higher score, and the higher level of efficiency. The Cronbach coefficient of the questionnaire is 0.764 .

(2) Learning Strategy Questionnaire: Referring to self-monitoring learning questionnaire drawn up by Dong and Zhou and Weinstein's standardized learning strategy scale, and combining with specific situation that higher vocational students learn foreign language, and finally a total of 43 questions are included in the questionnaire. It mainly the measures students' application level of meta-cognitive strategies, cognitive strategies and self-regulation strategies in foreign language learning. Ways of evaluation adopt a six-point system, and the higher score, the higher strategic level. The Cronbach's coefficient of the questionnaire is 0.856 .

(3) Interest level questionnaire: Referring to Cook interest level scale combining with the real English learning situation, and forming a total of 11 levels and the marks is consistent to the level. From 1 to 11 points, the higher the score, the higher the level of interest. The coefficient of internal consistency is 0.678 .

(4) Anxiety level questionnaire: Making a level description to the extent of anxiety students feel when they are learning and speaking English in the classroom as well as when they are practicing English in extracurricular learning. It is arranged from strong anxiety to moderate anxiety. The higher the score, the more moderate the level of anxiety. The coefficient of internal consistency is 0.660 .

(5) Motivation level questionnaire: Referring to Biggs' study process questionnaire, and using three dimensions: surface motivation, deep motivation, achievement motivation. And combining with learning characteristics of foreign language majors at higher vocational college, 14 questions are established. It adopts six-point system, and divides into three levels. The higher the score, the higher the motivation level. The coefficient of internal consistency is 0.850 .

(6) Attribution Questionnaire: Referring to the achievement attribution questionnaire compiled by Craudel and combining with the knowledge of attribution classification in educational psychology and students' actual situation. The questionnaire consists of 26 questions, divides into three categories and adopts a six-points scoring system: easy to control internal attribution. (-6-to-1 points); difficult to control internal attribution. (-5 to 1 points); difficult to control external attribution ( 1 to 6 points). The coherence coefficient of the questionnaire $=$ 0.780 .

(7) Motivation behavior dependent variables (see Table 1): Scores of initiative, perseverance and professional courses grades (intensive reading and listening) at last semester are classified into standardized scores, after the ratio of 1: 1: 1 Plus the total number of motivational behavior data. According to the definition of foreign language learning motivation behavior, it mainly includes learning initiative, the extent of efforts expended, as well as learning perseverance. This paper quantifies three standards combining with classification standards of three categories of students: the initiative of foreign language learning is reflected in frequency of note-taking, preview and review; perseverance is reflected in attendance and the frequency of homework; the extent of efforts is reflected in professional courses grades (intensive reading and listening) at last semester. To a much greater extent, grades reflect students' efforts. Therefore, the behavioral expression of foreign language learning motivation can be quantified as follows: frequency of note-taking and preview and review situation, attendance rate and frequency of homework, professional courses intensive reading grade and listening grade). Each 
performance scores in four levels, from "never" (0 points), "sometimes" ( 3 points), "often" ( 5 points) to "every time" (7 points).

\subsection{Research Procedures}

(1) Firstly, after the final exam, questionnaires should be issued immediately, and put answers into classification, each student's score is totaled by serial number. Secondly, these data are inputted into computer to establish a variable database. Thirdly, do a correlation operation one by one on the basis of computer program. Finally based on the above, raw data are subjected to multiple regression analysis. That is to say we will first do a correlation analysis of the factors that affect the learning motivation behavior of the 3 kinds of students: weary students, unwilling students and willing students. In that step, we can easily settle the first research problem. Then multiple regression analysis of self-efficacy, anxiety, learning strategies and motivation levels on motivational behavior are carried out. Finally, according to the multiple regression analysis above, the standardized regression coefficient could be calculated, that is the path coefficient, then establishing the corresponding path model to solve the second research problem.

\section{Results}

\subsection{Weary Students}

(1) Analysis of the factors that affect the learning motivation behavior of students.

Table 1. The correlation analysis of the factors that affect the learning motivation and behavior of the students who are tired of learning

\begin{tabular}{|c|c|c|c|c|c|c|c|c|c|}
\hline & & 1 & 2 & 3 & 4 & 5 & 6 & 7 & 8 \\
\hline 1 & motivation behavior & $\begin{array}{ll}-- \\
--\end{array}$ & $\begin{array}{ll}-- \\
--\end{array}$ & & & & & & \\
\hline 2 & attribute & -0.061 & --- & & & & & & \\
\hline 3 & school environment & 0.203 & -0.362 & --- & & & & & \\
\hline 4 & self-efficacy & $0.574^{* *}$ & tegie & 0.088 & --- & & & & \\
\hline 5 & level of interest & 0.355 & -0.240 & $0.459^{*}$ & $0.381^{*}$ & -- & & & \\
\hline 6 & level of anxiety & $0.559^{* *}$ & -0.272 & 0.343 & $0.422^{*}$ & $0.622^{* *}$ & --- & & \\
\hline 7 & learning strategy & $0.805^{* *}$ & 0.000 & 0.049 & $0.598^{* *}$ & 0.152 & $0.448^{*}$ & --- & \\
\hline 8 & level of motivation & $0.520^{* *}$ & 0.037 & $0.470^{*}$ & 0.023 & 0.250 & 0.116 & 0.225 & -- \\
\hline
\end{tabular}

The related data of Table 1 show that there is a high positive correlation between learning strategies and motivation behavior $(\mathrm{r}=0.805, \mathrm{P}<0.01)$. Self-efficacy, anxiety level and motivation level are moderate positively correlated with motivational behavior. School environment, interest level and the motivation behavior have a low positive correlation with motivational behavior. There is a low negative correlation between attribution and motivation behavior.

(2) Multiple regression analysis of self-efficacy, anxiety, learning strategies and motivation levels on motivational behavior are carried out. Stepwise regression analysis method finds that learning strategy has a significant regression effect on self-efficacy and anxiety levels; self-efficacy constitutes a significant regression effect on learning strategies; Learning strategies and motivation levels together constitute a significant regression effect on motivational behavior. The standardized regression coefficient and the significance level are shown in Table 2. The multiple regression analysis above shows that learning strategies are predictor of motivational behavior $(\mathrm{Q}=0.72410)$.

Table 2. Multiple regression analysis parameters that affect the learning strategies, motivation levels and motivation behaviors of students with learning disabilities

\begin{tabular}{lllllllll}
\hline & \multicolumn{2}{c}{ self-efficacy } & \multicolumn{2}{c}{ level of anxiety } & \multicolumn{2}{l}{ learning strategy } & \multicolumn{2}{l}{ level of motivation } \\
\cline { 2 - 9 } & $\beta$ & $\mathrm{P}$ & $\beta$ & $\mathrm{P}$ & $\beta$ & $\mathrm{P}$ & $\beta$ & $\mathrm{P}$ \\
\hline self-efficacy & & & & & 0.598 & 0.005 & & \\
level of anxiety & & & & & & & & \\
learning strategy & & 0.005 & & & 0.448 & 0.048 & 0.724 & 0.000 \\
level of motivation & & & & & & & 0.357 & 0.008 \\
\hline
\end{tabular}

(3) The route mode between motivation level, learning strategy, self-efficacy and motivational behavior. 
According to the multiple regression analysis above, the standardized regression coefficient could be calculated, that is the path coefficient, then establishing the following path model:

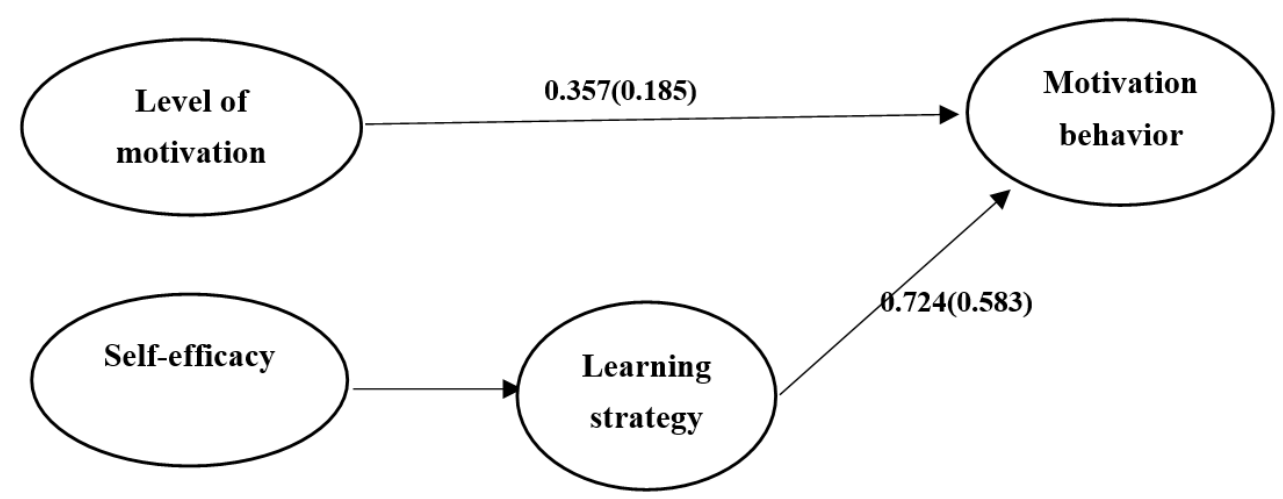

Figure 1. The route mode between motivation level, learning strategy, self-efficacy and motivational behavior Note: The value in brackets is R-squared of independent variable to dependent variable. $\mathrm{R}$ 'is the total coefficient of determination.

From this path model, it can be clearly seen that motivation levels and learning strategies have a direct influence on students' motivational behavior, while self-efficacy indirectly affects motivational behavior by influencing the learning strategies. Motivational behavior is predicted by learning strategies and motivation levels, and its coefficient of determination is $0.768(\mathrm{P}=0.000)$. That is to say, learning strategies and motivation levels explain $77 \%$ of variance of motivational behavior. If the correlation coefficient between independent variable and the motivation behavior is multiplied by the path coefficient of the independent variable to the motivation behavior, that is, taking $\mathrm{R}^{*} \beta$ as the coefficient of determination of the independent variable to the motivational behavior, the explanatory power of the learning strategies is the largest, which can explain the $58 \%\left(\mathrm{R}^{*} \beta=0.583\right)$ variation of the motivational behavior, and motivation level can explain the $19 \%\left(\mathrm{R}^{*} \beta=0.185\right)$ variation in motivational behavior.

\subsection{Unwilling Students}

Table 3. Correlation analysis of the factors that influence the motivational behavior of unwilling students

\begin{tabular}{|c|c|c|c|c|c|c|c|c|c|}
\hline & & 1 & 2 & 3 & 4 & 5 & 6 & 7 & 8 \\
\hline 1 & motivation behavior & --- & $\begin{array}{c}-- \\
--\end{array}$ & & & & & & \\
\hline 2 & attribute & $0.425^{*}$ & --- & & & & & & \\
\hline 3 & school environment & -0.035 & -0.419 & --- & & & & & \\
\hline 4 & self-efficacy & $0.500^{*}$ & 0.229 & -0.017 & --- & & & & \\
\hline 5 & level of interest & 0.107 & -0.132 & 0.065 & 0.290 & --- & & & \\
\hline 6 & level of anxiety & $0.418^{*}$ & -0.232 & -0.312 & 0.137 & -0.268 & --- & & \\
\hline 7 & learning strategy & $0.957^{* *}$ & $0.417 *$ & -0.056 & $0.542 * *$ & 0.248 & $0.456^{*}$ & --- & \\
\hline 8 & level of motivation & $0.517^{* *}$ & 0.154 & 0.003 & 0.178 & -0.216 & 0.108 & 0.374 & - \\
\hline
\end{tabular}

(1) Correlation analysis of the factors that influence the motivational behavior of unwilling students.

The correlation analysis in Table 3 shows that learning strategies positively correlated with the motivational behavior $(\mathrm{r}=0.945, \mathrm{P}<0.01)$. The attribution, self-efficacy, anxiety levels and motivation levels have a medium positive correlation with the motivational behavior. Interest levels show a low positive correlation with motivational behavior. School environment has a low negative correlation with motivational behavior.

(2) Multiple regression analysis of attribution, self-efficacy, learning strategies, and motivation levels on motivational behavior

The stepwise regression method shows that learning strategies and attribution have a significant regression effect on self-efficacy. Attribution and self-efficacy constitute a significant regression effect on learning strategies. Learning strategies and motivation levels constitute a significant regression effect on motivational behavior. The standardized regression coefficient and significance level are shown in Table 4. 
Table 4. The standardized multiple regression analysis of the factors affecting the learning strategy of unwilling students

\begin{tabular}{lllllll}
\hline & \multicolumn{2}{c}{ self-efficacy } & \multicolumn{2}{c}{ learning strategy } & \multicolumn{2}{c}{ motivation behavior } \\
\cline { 2 - 7 } & $\beta$ & $\mathrm{P}$ & $\beta$ & $\mathrm{P}$ & $\beta$ & $\mathrm{P}$ \\
\hline attribute & -0.552 & 0.007 & 0.572 & 0.002 & & \\
self-efficacy & & & 0.637 & 0.000 & & \\
learning strategy & 0.772 & 0.000 & & & 0.888 & 0.000 \\
level of motivation & & & & & 0.185 & 0.008 \\
\hline
\end{tabular}

The multiple regression analysis above shows that learning strategies and attribution could predict self-efficacy, and Learning strategies are highly predictive of self-efficacy $(\mathrm{p}=0.752)$ while attribution has a negative effect on self-efficacy whose predictability is also high $(\mathrm{p}=0.562)$. If attribution and self-efficacy predict learning strategies, self-efficacy is more predictive of the use of learning strategies. $(\mathrm{p}=0.653)$. Among them, the learning strategies have the highest predictability of motivational behavior $(p=0.878)$.

(3) Path model between motivation levels, learning strategies, self-efficacy, attribution and motivational behavior

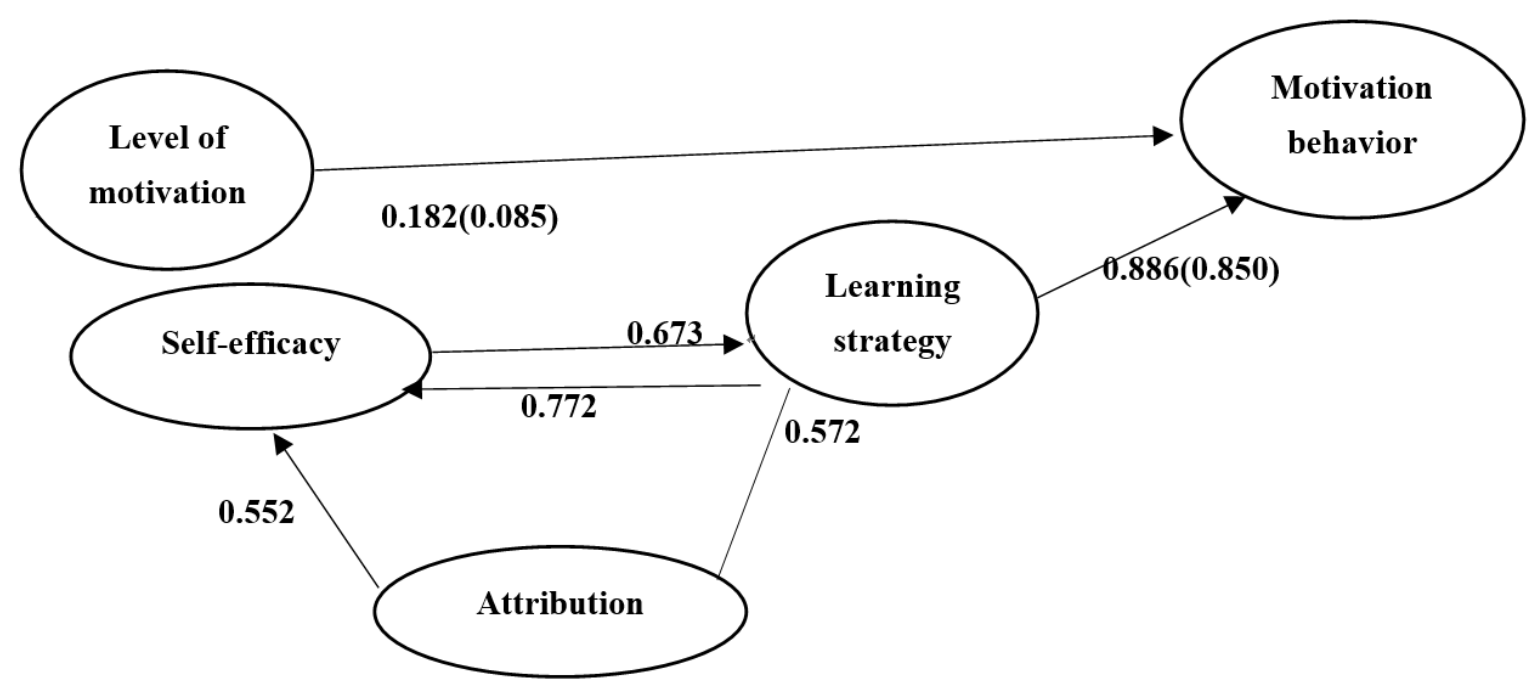

Figure 2. Path model between motivation levels, learning strategies, self-efficacy, attribution and motivational behavior

It can be clearly seen from the model that motivation levels and learning strategies have a direct influence on students' motivational behavior, while self-efficacy and attribution indirectly affect motivational behavior by influencing the learning strategies. Motivational behavior is predicted by learning strategies and motivation levels, which coefficient of determination is $0.935(\mathrm{P}=0.000)$, that is, learning strategies and motivation levels can explain $96 \%$ variation of the motivational behavior. The learning strategy and the motivation level can explain the motive behavior. If the correlation coefficient between independent variable and the motivation behavior multiplied by the path coefficient of the independent variable to the motivation behavior, that is, taking $\mathrm{R}^{*} \beta$ as the coefficient of determination of the independent variable to the motivational behavior, the explanatory power of the learning strategy is the largest, which can explain the $86 \%(\mathrm{R} * \beta=0.860)$ variation of the motivational behavior, and motivation levels can explain the $10 \%(\mathrm{R} * \beta=0.096)$ variation in motivational behavior.

\subsection{Willing Students}

(1) The data in Table 5 show that learning strategies have a high positive correlation with motivational behavior $(\mathrm{R}=0.916, \mathrm{P}<0.01)$. Self-efficacy and motivation levels have a medium positive correlation with motivational behavior. Attribution, school environment, interest levels and anxiety levels have a low positive correlation with motivational behavior. 
Table 5. Correlation analysis of various factors influencing the learning motivation of willing students

\begin{tabular}{|c|c|c|c|c|c|c|c|c|c|}
\hline & & 1 & 2 & 3 & 4 & 5 & 6 & 7 & 8 \\
\hline 1 & motivation behavior & -- & & & & & & & \\
\hline 2 & attribute & 0.037 & --- & & & & & & \\
\hline 3 & school environment & 0.003 & -0.283 & --- & & & & & \\
\hline 4 & self-efficacy & $0.432 *$ & -0.039 & -0.195 & --- & & & & \\
\hline 5 & level of interest & 0.159 & -0.429 & -0.164 & 0.209 & --- & & & \\
\hline 6 & level of anxiety & 0.179 & 0.284 & -195.000 & 0.180 & 0.256 & --- & & \\
\hline 7 & learning strategy & $0.910^{* *}$ & 0.033 & 0.045 & 0.367 & -0.007 & 0.076 & --- & \\
\hline 8 & level of motivation & $0.549 * *$ & -0.028 & -0.060 & 0.292 & 0.347 & 0.168 & 0.248 & -- \\
\hline
\end{tabular}

(2) Multiple regression analysis of learning strategies and motivation levels on motivational behavior

From stepwise regression method, it can be seen that learning strategies and motivation levels have a significant regression effect on the motivational behavior. The standardized regression coefficient and significance levels are shown in Table 6.

The multiple regression above shows that learning strategies and motivation levels can predict motivational behavior, and learning strategies are highly predictive of motivational behavior $(\mathrm{p}=0.816)$.

Table 6. Multiple stepwise regression analysis of factors affecting the learning strategies of willing students

\begin{tabular}{lll}
\hline motivation behavior & $\beta$ & $\mathrm{P}$ \\
\hline learning strategy & 0.816 & 0.000 \\
level of motivation & 0.344 & 0.0 \\
\hline
\end{tabular}

(3) Path mode between motivation levels and learning strategies on motivational behavior

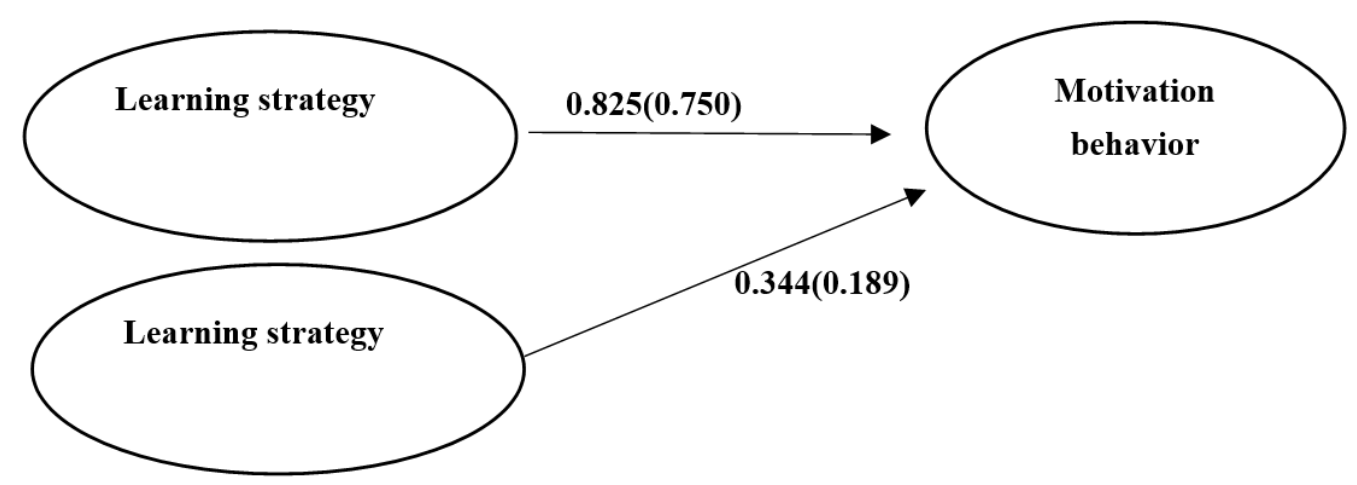

Figure 3. Path mode between motivation levels and learning strategies on motivational behavior

From this path mode, it can be clearly seen that motivation levels and learning strategies have a direct influence on students' motivational behavior, while self-efficacy indirectly affects motivation behavior by influencing the learning strategies. Meanwhile, motivation behavior is predicted by learning strategies and motivation levels, and its coefficient of determination is $0.949(\mathrm{P}=0.000)$. That is to say, learning strategies and motivation levels explain $95 \%$ of variance of motivation behavior. If the correlation coefficient between independent variable and motivation behavior multiplied by the path coefficient of the independent variable to motivation behavior, that is, taking $R^{*} \beta$ as the coefficient of determination of the independent variable on motivational behavior, the explanatory power of the learning strategies is the largest, which can explain the $76 \%(\mathrm{R} * \beta=0.760)$ variation of the motivational behavior, and motivation levels can explain $18 \%\left(\mathrm{R}^{*} \beta=0.18\right)$ variation in motivational behavior.

\section{Discussion}

There are universality and individuality in factors predicting the motivational behavior of three categories of students. Therefore, countermeasures are different in stimulating students' foreign language learning motivation. Predictive factors of motivational behavior include motivation levels and learning strategies, and R-squared is 
greater than 0.768 . The regression effects of learning strategies on motivational behavior are the greatest in the three categories of path analysis. Among them, weary class $\mathrm{R}^{\prime}=0.583$, unwilling class $\mathrm{R}^{\prime}=0.850$, willing class R' $=0.750$. It shows that learning strategies determine the performance of their motivational behavior, at the same time, it shows individual variance. For weary students, self-efficacy constitutes a significant regression effect on learning strategies $(\beta=0.598, \mathrm{P}<0.000)$, which indirectly affects motivational behavior by influencing learning strategies. For unwilling students, there is a significant regression effect on the three factors of self-efficacy, attribution and learning strategies. Using attribution and self-efficacy to predict learning strategies, self-efficacy has a higher predictability for learning strategies than attribution $(\beta=0.673)$ and attribution also has a high predictability $(\beta=0.572)$. For willing students, there are only two factors that constitute significant regression effects on predictability of motivational behavior, learning strategies and motivation level, and the rest have no significant regression effect. Here are some suggestions. Firstly, teachers could transmit related knowledge to students, instructing correct cognitive strategies, cultivating meta-cognitive strategies, teaching students to monitor their behavior, and implementing planned things so that students could form strong perseverance and willpower. Secondly, cultivating students' society strategies (such as seeking support strategies) and resource management strategies (such as time management, learning environment management, and effort management), which are key to achieve a good motivational behavior. Then recommendations for individuality: for weary students, a higher self-efficacy should be developed, motivation levels should be improved, and a better sense of learning strategy should be cultivated, which is the key to improve their motivational behavior. For unwilling students, correct attribution beliefs should be strengthened, higher self-efficacy should be cultivated, motivation levels should be raised again, and better learning strategies should be cultivated. For willing students, it is crucial to cultivate them a better sense of learning strategies and improve their motivation levels, so they could obtain a better motivational behavior.

There are some limitations of this study that were important to contextualize findings and that provide direction for future research. Firstly, the sample was higher Vocational College Students. As differences in students' real-time engagement have been found between countries future replication of the current findings in other contexts are necessary. Future research might explore similar questions as ours using multiple teacher ratings. Thirdly, the lagged analysis can be carried out, and more time-points are needed for any future time-series types of analyses. Fourthly, while our discrete time approach was consistent with the organization of students' lesson time-tables in school during a week, a continuous time approach could reveal interesting effects of actual distances in time-lags between educational experiences. Hence, there is a need for further research that can expand the scope of this study beyond the different types of students with their respective institutions. To make this idea more comprehensive, we encourage further investigations and discoveries for more factors responsible for motivating instructors. Additionally, these studies will provide a more complete idea of the motivation towards the effective application of teaching methods across different categories of students with their institutions.

\section{References}

Govender, L. (2009). Teachers' Participation in Policy Making: The Case of the South African Schools Act. PhD dissertations, University of the Witwatersrand.

Littlejohn, A., \& Pegler, C. (2007). Preparing for blended e-learning. Routledge. https://doi.org/10.4324/9780203961322

Mackenzie, N., \& Knipe, S. (2006). Research dilemmas: Paradigms, methods and methodology. Issues in Educational Research, 16(2), 193-205.

Masrom, U., \& Md. Yusof, D. S. (2013). English Games as a Constructivist Approach in Project Based Learning. International Journal of Social Science and Humanities Research, 1(1), 21-25.

Pituch, K. A., \& Stevens, J. P. (2009). Applied multivariate statistics for the social sciences (6th ed., Vol. 21). New York and London: Routledge.

Shanthi, W. G., \& Rao, A. R. (2015). Project Based Learning: An Effective Tool for Developing Aural and Oral Skills of Engineering Students-A Study (pp. 9-11). In International Conference on Humanities, Literature and Management.

Thi, N. V. L. (2011). Project-based Learning in Teaching English as a Foreign Language. VNU Journal of Science, Foreign Languages, 27, 140-146.

Tomei, L. A. (2005). Taxonomy for the technology domain. USA: Information Science Publishing. https://doi.org/10.4018/978-1-59140-524-5.ch005 
Zhang, Y. (2015). Project-based Learning in Chinese College English Listening and Speaking Course: From Theory to Practice. Canadian Social Science, 11(9), 40-44.

\section{Copyrights}

Copyright for this article is retained by the author, with first publication rights granted to the journal.

This is an open-access article distributed under the terms and conditions of the Creative Commons Attribution license (http://creativecommons.org/licenses/by/4.0/). 